\title{
Uma antropologia do crime: comentários do Marquês de Sade sobre os povos da América
}

\author{
Guilherme Grané Diniz (USP)*
}

https://orcid.org/0000-0002-9324-0083

\section{Resumo:}

O Marquês de Sade tem como preocupação teórica a defesa argumentativa do crime. É comum que seus personagens lancem mão de argumentos diversos na justificativa da moralidade das ações que nossa sociedade considera criminosas. Uma forma recorrente na defesa dessa tese é o recurso à antropologia. Sade observa costumes de outros povos - os americanos inclusive - ressaltando como neles condutas que nós consideramos crimes não o são, e vice-versa. Parece que observar o modo como Sade procede a esse tipo de análise nos esclarece duplamente. Primeiro, poderíamos entender melhor esse tópico relevante de sua obra. Em segundo lugar, isso é ilustrativo de como Sade representa uma forma incomum da recepção das descobertas da época. É corrente o entendimento de que a antropologia - derivada de relatos de viagem focados principalmente no caráter "exótico" dos costumes e leis desses povos - surge em consonância e reforço do projeto colonialista. 0 pensamento evolucionista que marca a antropologia do tempo dá a entender que os europeus eram superiores aos americanos e outros povos, tendo o direito de dominá-los e colonizá-los. Ora, para Sade, as culturas desses povos mostram uma possibilidade de descentrar o olhar do pensamento europeu para compreender diferentes modos de sociabilidade.

Palavras-chave: Marquês de Sade. Antropologia. Pierre Clastres. Thomas Hobbes. Linguagem.

\section{Résumé:}

\section{Une Anthropologie du Crime: Commentaires du Marquis de Sade sur les peuples Americains}

Le marquis de Sade a pour préoccupation théorique la défense argumentative du crime. Il est courant que ses personnages utilisent différents arguments pour justifier la moralité des actes que notre société considère comme criminels. Le recours à l'anthropologie est une forme récurrente dans la défense de cette thèse. Sade observe les coutumes d'autres peuples

* Mestre em Filosofia e Teoria Geral do Direito pela FD-USP e doutorando em Filosofia pela FFLCH-USP. E-mail: guilhermegranediniz@gmail.com. 
- y compris les Américains - en soulignant qu'ils ne les considèrent pas comme des crimes et vice-versa. Il semble que l'observation de la manière dont Sade conduit ce type d'analyse peut nos eclairer doublement. Premièrement, nous pourrions mieux comprendre ce sujet pertinent de son travail. Deuxièmement, cela illustre comment Sade représente une manière inhabituelle de recevoir les découvertes de l'époque. Il est communément admis que l'anthropologie - dérivée de récits de voyage axés principalement sur le caractère «exotique» des coutumes et des lois de ces peuples - s'inscrit dans le prolongement du projet colonialiste et s'en renforce. La pensée évolutionniste qui caractérise l'anthropologie de l'époque implique que les Européens étaient supérieurs aux Américains et aux autres peuples, qu'ils avaient le droit de les dominer et de les coloniser. Pour Sade, les cultures de ces peuples montrent une possibilité de décentraliser le regard de la pensée européenne pour comprendre différents modes de sociabilité.

Mots-clés: Marquis de Sade. Anthropologie. Pierre Clastres. Thomas Hobbes. Language.

É uma tese já clássica do pensamento antropológico aquela que associa, nas sociedades indígenas, guerra e economia. Em ensaio sobre a questão, Carlos Fausto (1999, p. 256) elenca e discute algumas delas - notadamente, a ecologia cultural e sociobiologia - e propõe uma visão alternativa a respeito da questão. Um elemento que tanto sua tese quanto as outras apresentadas têm em comum é a percepção de que boa parte do que os povos indígenas praticam como guerra não diz respeito tanto às ações efetivas de violência, mas a seus aspectos simbólicos (FAUSTO, 1999, p. 265). Poderíamos, ainda, dizer: as explicações para o fenômeno da guerra entre os povos indígenas que visam enfatizar seus aspectos mais, por assim dizer, "diretos" ou "utilitários - disputas territoriais; convívio entre culturas incompatíveis; disputa por recursos escassos como mulheres, terras férteis ou fontes de proteína, etc. - falham, posto que fazem a guerra aparecer como um fenômeno quase que de ordem natural, ou uma resposta social a uma demanda que é natural em sua origem. Falham, assim, em compreender o as- pecto eminentemente social do ato de guerra (FAUSTO, 1999, p. 257). Há, ainda, dois elementos importantes para compreender a questão. Primeiramente, que esse aspecto simbólico da violência pode ser descrito mais detalhadamente como sendo um aspecto linguístico. Trata-se, como aponta Fausto (e como Clastres já mostrara), de ritos que envolvem a capacidade de nomear ou renomear as coisas e pessoas; da canibalização não apenas da carne, mas dos nomes e qualidades do oponente, etc. Clastres (1974) deixa bastante evidente esse aspecto em sua análise do papel da tortura na sociedade indígena. As cicatrizes deixadas sobre o corpo dos jovens torturados equivaleriam à escrita da lei, mas em um suporte em virtude do qual ela nunca poderá vir a ser ignorada. A tortura é, ela mesma, uma forma de linguagem, mas em uma visão de mundo na qual linguagem e corpo não são coisas distintas. Ora, justamente, o segundo elemento para compreender a questão é o contexto cosmológico no qual se insere essa visão sobre a linguagem. Ora, esse ato de nomeação possibilitado pela guerra deve ser pensa- 
do no contexto de uma visão da linguagem oposta a todo nominalismo: o nome que se dá a uma coisa não é simples som que a designa ou significa, mas está intrinsecamente ligado a ela e a sua essência. 0 aspecto simbólico-ritual da violência diz respeito ao fato de que esse processo de "renomeação" envolve uma verdadeira transformação no ser da coisa nomeada (como bem estabelecido por Viveiros de Castro (2018).

Fausto mostra como, do ponto de vista da história do pensamento, essa questão sobre os sentidos da guerra entre os povos ditos primitivos tem uma alçada muito relevante: sabemos como as teorias políticas contratualistas envolvem todas uma reflexão sobre como seria o estado natural, pré-societal, do ser humano; considerando que, nesse contexto, entende-se por sociedade apenas aquelas que têm Estado. No séc. XVIII, ao mesmo tempo em que esse tipo de reflexão se consolida e encontra suas formulações mais acabadas, intensificam-se as "descobertas" acerca dos povos nativos da América e da África, amplamente divulgadas através de relatos de viagens. Os povos "primitivos" aí descobertos seriam como que ilustração ou mesmo prova empírica das teses acerca do homem em seu estado natural, uma vez que, pela primeira vez, o homem europeu se deparava com sociedades organizadas sem um Estado. A percepção de que esses povos eram "selvagens", "ferozes", "violentos", "canibais" e etc., coloca, no entanto, um problema significativo para certas visões filosóficas que se baseavam sobre uma antropologia mais "pacífica", como a de Rousseau. A visão hobbesiana, além de ganhar um forte testemunho empírico, pareceria a única capaz de teorizar adequadamente acerca da rudeza da vida primitiva; mas isso especialmente na medida em que propõe uma ruptura clara com esse estado de natureza.
No mais, fazia com que o recurso retórico à natureza humana como parâmetro normativo para a vida política, jurídica e social em geral encontrasse fosse mais difícil. A retórica naturalista deveria lidar com a natureza "má" do homem.

Ora, nenhuma dessas questões que delineamos mais acima é inédita. No entanto, pretendemos fazer, neste texto, uma abordagem teórica que nos parece não ter sido tentada até então. Dentre os autores desse primeiro momento de reflexão sobre as sociedades indígenas, entre os séculos XVI e XVIII, vale destacar o Marquês de Sade. Assim como Hobbes, Sade supõe uma antropologia na qual o homem é um ser violento e propenso à agressão. Assim como Rousseau, é da ideia de que a natureza é um guia relevante e desejável para a construção racional e refletida da sociedade. Escrevendo quase dois séculos depois de Hobbes, Sade tem os relatos etnográficos já como um de seus principais pontos de partida, não como prova suplementar a sua reflexão teórico-conceitual. Ao contrário de Hobbes, Sade não hesita em extrair as consequências mais radicais de uma visão naturalista: sendo a maldade natural ao homem, cabe aceitarmos e ativamente endossarmos essa natureza.

De fato, Sade fez de toda sua obra uma reflexão sobre a violência. Seus escritos são notórios pelo modo como conjugam o retrato sexual explícito com uma insistência quase que patológica (não por acaso autores como Bloch e Kraft-Ebbing cunham o termo "sadismo" para descrever esse autor, sua obra e os comportamentos sexuais que ele retrata) na descrição da violência. Mas, mais ainda, tratou de refletir sobre a própria forma e condição da linguagem filosófico-literária da qual se utiliza. Enquanto gênero, o romance filosófico certamente não é uma 
invenção sadeana; pelo contrário, era uma forma bastante difundida à época. Não obstante, sua escolha por essa forma não é em nada ingênua. De maneira resumida (detalharemos adiante), Sade considera que todo conhecimento filosófico repousa sobre estímulos de ordem afetiva, sexual. 0 desejo é o motor inicial de toda investigação filosófica, e a adesão a uma ou outra tese passa mais pela interação dela com aspectos psico-afetivos do leitor ou auditório do que de seu conteúdo estritamente lógico-argumentativo. Nesse sentido, faz-se necessário encontrar modos de escrita e exposição que permitam aproximar os conteúdos das teses filosóficas expostas dos afetos do corpo e do desejo: daí a associação tão peculiar entre literatura erótica e filosofia. Enfim - e este é um dos pontos mais singulares de sua escrita - Sade não deixou de propor uma cosmovisão. Sua antropologia naturalista, que tem como um de seus corolários uma visão materialista da linguagem, envolve também uma tentativa de explicação cosmológica acerca da natureza enquanto tal, na qual se articulam essa visão sobre a linguagem, a violência e o aspecto genésico. Conforme mostraremos, mesmo que pelo filtro dos relatos dos viajantes, a filosofia de Sade - em todos esses seus aspectos - é informada por uma reflexão acerca dos povos indígenas.

Nesse sentido, este trabalho se propõe algumas tarefas: primeira e principalmente, mostrar como opera a reflexão de Sade sobre os povos indígenas. Acabamos de mencionar que vários elementos centrais do pensamento sadeano passam pela reflexão sobre os povos indígenas. Observarmos essa reflexão permitirá elucidar um ponto central do pensamento sadeano. Em segundo lugar, mostrar como Sade pretende, através de sua literatura, refazer certas articulações entre violência e linguagem que ele já iden- tificava nesses povos. De fato, autores como Clastres, Viveiros de Castro e Carlos Fausto, mesmo que sem uma leitura direta da obra sadeana, acabam por se aproximar em muitos termos e temas de sua visão antropológica, na medida em que buscar apresentar de maneira positiva os elementos simbólicos da violência indígena, especialmente em suas decorrências políticas. Enfim, ser um exemplo de como poderíamos mobilizar o pensamento do Marquês de Sade de maneira mais instrumental, usando de sua filosofia como grade teórica dentro da qual refletir sobre questões diversas. Ou seja, habilitar (mas apenas de maneira exemplificativa) a possibilidade de uma investigação ou análise "sadeana", no mesmo sentido que se fala de um estudo feito à maneira "foucaultiana”, “cartesiana”, etc. No caso, trata-se de oferecer uma análise sadeana sobre as relações entre violência, corpo e linguagem nas sociedades indígenas.

Podemos começar lendo em Hobbes a seguinte afirmação:

os povos selvagens da América, com exceção do governo de pequenas famílias, cuja concórdia depende da concupiscência natural, não possuem qualquer espécie de governo, e vivem em nossos dias daquela maneira embrutecida que acima referi (HOBBES, 1988, p. 80).

É comum se apontar como, para Hobbes, a reflexão sobre o estado de natureza é apoiada sobre a postulação de axiomas e a dedução de corolários lógicos, de forma que independe de análises sobre a existência efetiva desse estado. Esse trecho, no entanto, não permite duvidar que Hobbes tinha em mente a existência concreta de sociedades em estado de natureza: "os povos selvagens da América”. A distância que separa Hobbes de um pensamento antropológico mais recente também separa os 
valores atribuídos aos modos de vida dos povos "primitivos", bem como projetos políticos que ambos veiculam. Mas essa distância, é importante reparar, não se deve primeiramente aos dados etnográficos (que à época eram somente dados anedóticos de relatos de viagem) que embasam essas concepções divergentes. Para Hobbes, o homem em seu estado de natureza é desprovido de todo refinamento intelectual e sempre disposto e propenso à agressão. A tão famosa "guerra de todos contra todos" hobbesiana decorre da falta de limites do desejo humano, que, sem uma mão forte que lhe refreie, inevitavelmente leva ao conflito e à barbárie. Mas quando lemos em Pierre Clastres (1974, p. 155) a seguinte descrição dos ritos de passagem indígenas: "buracos abertos nos corpos, espetos atravessados nas chagas, enforcamento, amputação, a última corrida, carnes rasgadas" - acabamos ficando com a impressão de que a caracterização hobbesiana genérica do homem natural como um animal desprovido de intelectualidade e senso moral, na verdade, fica muito aquém da violência real e bastante refinada encontrada entre esses povos americanos.

A distância valorativa entre aqueles dois modos de pensar os dados antropológicos tem por objeto primeiro uma característica fundamental da configuração política dessas sociedades: a ausência de Estado. Diferente de nossas sociedades, ocidentais, entre os "primitivos" o poder se encontra difuso na coletividade do grupo. Não há um polo no qual ele se concentra e a partir do qual se ordena, como que de fora, uma vida social que lhe é fundamentalmente alheia. Para Hobbes (segundo Clastres) - isso é verdadeiro porém indesejável: uma sociedade que falha em distinguir de si o poder político, fixando-o na forma do Estado - ainda mais grave que padecer de um estado de guerra, violência, crueldade - é uma sociedade que desconhece a moral e a justiça, vivendo apenas segundo seus instintos naturais. De fato, Clastres argumenta que desde o surgimento do pensamento político no ocidente, sociedade e Estado são compreendidos como sendo coexistentes em sua dualidade: onde não houvesse Estado, sequer poderíamos falar de uma vida propriamente social. Faltando à vida de cada pessoa o elemento de sociabilidade que, justamente, é o aspecto próprio da humanidade, quem vive sem Estado não seria em nada diferente ou superior a um animal inteligente.

Segundo Clastres, os povos livres da América não desconheceram de todo essa articulação, mas, intuindo-a, fazem-na operar de outra forma. Mais que simplesmente "sem fé, sem lei e sem rei", como acreditaram os primeiros colonizadores, tratava-se de sociedades cujas práticas e instituições se constituíam de modo a especificamente impedir a formação do Estado enquanto lugar do poder distinto da sociedade. No ensaio ao qual nos referimos mais acima, Clastres discute os sentidos da tortura entre os indígenas. Observa que, entre eles, a tortura é uma instituição da vida política; mais especificamente, cumpria a função de um rito de passagem. Para a aceitação plena do indivíduo na sociedade era necessária a inscrição no próprio corpo, sob a forma de uma memória encarnada, da lei daquela sociedade. As cicatrizes que resultam do rito são os significantes de uma verdadeira linguagem (mesmo que não plenamente articulada) cujo texto é a lei daquela sociedade. É a conjunção entre lei e corpo que garante que cada indivíduo seja o portador da relação jurídica central dessas sociedades indígenas - a igualdade. Inscrita no corpo, portanto indistinta de seu destinatário, a lei da 
igualdade entre poder e sociedade e entre os indivíduos garante, por sua própria estrutura, seu cumprimento:

A suas crianças, a tribo proclama: vocês são todos iguais, nenhum entre vocês vale mais que outro, nenhum menos que outro, a desigualdade é proibida pois ela é falsa, ela é má. E para que não se perca a memória da lei primitiva, ela é inscrita, em marcas iguais, dolorosamente recebidas, sobre os corpos dos jovens iniciados no saber dessa lei. No ato iniciático, o corpo individual, como superfície de inscrição da Lei, é o objeto de um investimento coletivo desejado pela sociedade como um todo, afim de impedir que, um dia, o desejo individual, transgredindo o enunciado da Lei, tente investir contra o campo social (CLASTRES, 1980, p. 120)

A distância entre Clastres e Hobbes - conotativa daquela entre a percepção clássica e a mais contemporânea acerca dos povos primitivos - parte desse âmbito sócio-político para só então dizer respeito à questão sobre o valor da violência. Pois, enquanto Hobbes enxerga nela uma força natural interna a cada um e desagregadora da sociabilidade que põe o homem plenamente de posse de sua humanidade, Clastres percebe nela uma intenção ativa e sistemática - cujo sentido é instaurar e garantir as formas de sociabilidade próprias desses grupos - da parte dos povos indígenas, de fazer a lei e a linguagem que lhe veicula circularem de um modo tal que o Estado não seja possível. A violência, aqui sob a forma da tortura, é a ferramenta pela qual se reafirma a lei da igualdade, impedindo a cisão entre poder e sociedade. No mais, a violência, mais que impulso natural, dado fisiológico ou problema político, é um verdadeiro elemento discursivo, central na enunciação do discurso jurídico dos povos ditos "primitivos".

Consideremos ainda outra das torturas narradas na obra de Clastres:
[...] cada um pegou um tição e queimava esse pobre miserável aos poucos, para fazê-lo padecer mais tormentos [...] depois arrancavam-lhe as unhas e puseram fogo na extremidade dos dedos e de seu membro. A seguir, esfolaram o alto da cabeça e ali derramaram uma goma muito aquecida; depois furaramlhe os braços junto aos pulsos e, com bastões, puxaram os nervos à força ... os arrancavam e cortavam. (CLASTRES, 2014, p. 284)

A semelhança dessa tortura - histórica e real - com as torturas literárias e fantasiosas narradas por Sade pode ser constatada com muita facilidade, e não é casual:

Lhe é enfiado um ferro quente na boceta e no cu [...] Isso feito, se descobrem seus ossos e eles são cortados em diferentes lugares. Depois são descobertos seus nervos em quatro lugares formando uma cruz. Cada ponta desses nervos é ligada a um torniquete, que é girado, o que lhe alonga essas partes delicadas e lhe faz sofrer dores inauditas. Lhe é dado um descanso para melhor fazê-la sofrer, depois a operação é retomada, e, dessa vez, os nervos são esfolados com um canivete (SADE, 1990, p. 371).

Não é casual, como dizíamos, pois Sade sabia terem sido os povos indígenas da América seus inventores, e se inspirava diretamente dos relatos antropológicos que as reportavam: "os iroqueses ligam as extremidades dos nervos de suas vítimas a bastões, e girando em seguida esses bastões, eles enrolam sobre eles os nervos como uma corda" (SADE, 1998, p. 895). Devemos notar que, esse trecho, Clastres cita dos relatos de viagem de Champlain, aos quais (apesar de não constarem de sua biblioteca ${ }^{1}$ ) Sade poderia ter tido acesso, posto que foram escritos no século XVII. Sabe-se que Champlain foi um autor relevante para a visão que a França tinha à época dos povos americanos, inclusive no que diz respeito a Démeunier, autor, esse

1 O inventário de seu acervo foi levantado na ocasião de sua morte. Cf. Lely (1973, p. 641-2). 
sim, que Sade cita reiteradamente e do qual tira pontos cruciais de sua visão antropológica (DELON in SADE, 1998, p. 1.529). No mais, Sade conhecia tanto a caracterização antropológica hobbesiana quanto sua teoria sobre a necessidade natural e imperativa de um Estado forte. Não apenas Sade menciona Hobbes diversas vezes em suas obras, mas, de fato, quanto à descrição antropológica, ao menos em seus aspectos gerais, sabemos que ambos estavam bem de acordo: os homens, em seu estado de natureza, são seres brutais, desprovidos de moralidade, propensos e desejosos de todo tipo de violência.

Existe um ponto no qual essa visão se mostra bastante bem articulada na obra de Sade: trata-se da dissertação do Papa Pio VI sobre o crime, na História de Juliette. Juliette, que a essa altura da história que leva seu nome era uma das maiores prostitutas de Roma, é pessoalmente convidada pelo Papa para participar de algumas orgias. Como uma de suas condições, Juliette exige que esse libertino tão escolado na carreira do vício lhe ensine alguns dos conhecimentos que juntou ao longo dos anos. Isso, é claro, não tão somente com fins acadêmicos, mas também como uma espécie de "aperitivo" que, justificando o crime e a libertinagem, aguce o apetite dos ouvintes para a orgia que se seguirá. Não é - bem pelo contrário o único discurso sadeano que pretende justificar a maldade. Também não é o único que mobilizará, como parte de sua argumentação, uma longa enumeração de modos pelos quais diversos povos praticaram o crime, justamente de forma a ficar patente a naturalidade do instinto criminoso no homem.

Vejamos os primeiros exemplos dados pelo Sumo Pontífice:

Em Cabo-de-Monte, se uma mulher dá à luz duas crianças de uma só vez, seu marido esmaga uma imediatamente.
Sabe-se o quanto os árabes e os chineses se importam com seus filhos, por pouco conservam metade. Eles assassinam, queimam ou molestam o resto, e principalmente as moças. Em Formosa, a progenitura tem o mesmo grau de horror (SADE, 1998, p. 886).

De partida, já podemos notar uma distância significativa em relação ao pensamento de Hobbes: parece errado supor que esses povos viviam uma vida pobre do ponto de vista da técnica e da intelectualidade. Pelo contrário, eles deram a suas capacidades de destruição refinamentos de todo tipo, dominando técnicas de tortura e desenvolvendo aparatos de alta complexidade para tanto: "não é suficiente matar, é necessário matar de uma maneira horrível" (SADE, 1998, p. 894). Mas, não apenas as conceberam, como até mesmo as louvavam como sendo moralmente relevantes e desejáveis: "quase todos os selvagens da América matam seus velhos quando os veem doentes; é uma obra de caridade da parte dos filhos; o pai o maldiz se ele não lhe mata, dado que é impotente" (SADE, 1998, p. 888). Ou, ainda, conferem ao assassinato um estatuto jurídico, regulamentando suas possibilidades e condições: "em Madagascar, todas as crianças nascidas às terças, quintas e sextas, são abandonadas às bestas ferozes, pelos próprios autores de seus dias" (SADE, 1998, p. 887). Hobbes se enganara ao assumir que entre esses povos a violência era natural, involuntária, que havia desejo por fazê-la cessar. Sade mostraria como para os povos primitivos a violência é um aspecto fundante e essencial da vida política, como Clastres viria a dizer mais de um século depois: eles a cultuavam, e nosso crime é sua virtude.

Concordarem nessa questão faz com que existam semelhanças realmente surpreendentes entre Sade e Clastres. As comparações que estabelecemos entre Clastres e 
Hobbes apontam, em primeiro lugar, uma torção em certo pensamento antropológico. Certamente que aqui falamos com algum grau de generalidade; no entanto, é marcante como nos primeiros passos da antropologia enquanto ciência, a tarefa intelectual posta para boa parte dos autores era mostrar a eminente superioridade dos povos europeus. Podemos observar isso em um exemplo bastante relevante: o pensamento de Henry Sumner-Maine. Trata-se de um autor relevante para o pensamento evolucionista na antropologia em geral e na teoria do direito, especificamente. 0 trabalho de Maine teria consistido em identificar "estágios sucessivos pelos quais todas 'sociedades progressivas' devem passar" (ELLIOT, 1985, p. 44). 0 estudo feito por esse autor acerca da história e antropologia do direito pretende mostrar como as formas jurídicas encontráveis nas diversas sociedades têm correlatos no desenvolvimento histórico de nossa própria sociedade, e que esse desenvolvimento tem o sentido de uma evolução. Especificamente, essa evolução significa uma passagem "do Status ao Contrato" (SUMNER-MAINE, 1936, p. 100).

0 modelo da evolução jurídica ocidental, segundo Sumner-Maine, seria o Direito Romano, que passa progressivamente de uma codificação inicial ao desenvolvimento de diversas teorias complexas acerca da jurisprudência, a qual se especializa em suas diversas áreas. 0 ápice da história evolutiva do direito seria a modernidade jurídica, na qual "o desenvolvimento do Direito Penal foi universalmente acelerado por duas causas, a memória do Império Romano e a majestade da Igreja" (SUMNER-MAINE, 1936, p. 233). Outros povos não tiveram o "privilégio" de conhecer o catolicismo, o que os deixa atrasados no desenvolvimento histórico do direito. Especificamente, o que o catolicismo introduziria e que seria o verdadeiro sentido da evolução é a mudança de paradigmas punitivistas: "no direito primitivo de quase todas as raças que popularam a Europa Ocidental existem vestígios da noção arcaica de que a punição de crimes pertence à assembleia geral de homens livres" (SUMNER-MAINE, 1936, p. 233). 0 que o cristianismo teria introduzido é a despersonalização da relação de punição, concentrando-a nas mãos de um órgão ou pessoa indicado exclusivamente para tal função (seria o papel do pacto ou contrato social). Em outras palavras, o que está em jogo é a reunião do "direito de recompensar com riquezas e honras, e o de punir com castigos corporais e pecuniários, ou com a ignomínia" (HOBBES, 1973, p. 115) na figura de um soberano. Existem, naturalmente, diferenças significativas entre ambos os autores, mas eles convergem não apenas na descrição linear, teleológica e geral dos processos históricos de todos os povos humanos, mas também em considerar que a emergência contratual do Estado moderno e seu poder despersonalizado são o ponto mais bem-acabado desse desenvolvimento. A modernidade do ocidente passa a se inscrever na própria natureza humana como seu fim imanente, gloriosamente realizado no homem europeu.

Atualmente, compreende-se que um pensamento de cunho evolucionista, antropológico ou não, constitui-se de dois elementos principais; um descritivo e um valorativo. Não apenas é necessária uma concepção linear da história ou da natureza humana, que permita comparar estágios de "desenvolvimento" entre sociedades e povos. Também é característico desse pensamento a ideia de que nossa sociedade é a mais desenvolvida, seja do ponto de vista técnico, político, social, cultural, etc. Nessa teleologia linear do desenvolvimento his- 
tórico, o pensamento evolucionista considera que fomos mais longe. Sendo assim, um pensamento que considerasse que não existe esse "percurso" natural do desenvolvimento e mudanças das formas sociais ao longo da história - ou que, considerando isso, não concluísse que nossos modos de vida são os superiores - não seria um pensamento evolucionista. Mesmo que à época de Hobbes não existisse uma antropologia no sentido científico específico que lhe atribuímos hoje, certamente uma ideia geral de evolucionismo estava presente. A ideia de que existe uma natureza humana cujo sentido fundamental é a violência, mas que apenas pode realizar seus potenciais mais altos de forma plena através da exigência racional - portanto, natural - de um Estado, garante que a história do desenvolvimento político das sociedades ocidentais não apenas seja necessária, mas que a criação do Estado, enquanto aparato técnico da vida política, as coloque em um patamar superior. A partir essa breve leitura de Sumner-Maine, vimos um exemplo significativo de como o pensamento antropológico evolucionista, ao menos em alguma medida, também pode ser caracterizado pela consideração de que a racionalização dos modos de vida é o sentido próprio de evolução e superioridade.

Existe um passo importante entre os primeiros momentos da modernidade vividos por Hobbes no XVII e o auge do positivismo, em cujo contexto Sumner-Maine escreve, no fim do XIX. Trata-se do Iluminismo do XVIII, que possibilita essa transição entre um regime anedótico e exploratório da antropologia para seu estudo científico metodologicamente informado ${ }^{2}$ : inauguração da modernidade. Esse é um processo bem descrito no As Palavras e as Coisas, de Foucault. Foucault

2 Essa sugestão foi dada em aula na FD-USP por prof. Orlando Villas-Boas Filho. considerará que o séc. XVIII foi um momento de passagem e ruptura na história intelectual e cultural do ocidente. Não por acaso, Sade teria sido uma das duas figuras intelectuais que desencadearam o processo (a outra foi Kant, que, com sua distinção entre númeno e fenômeno, teria feito um "gesto geminado" ao de Sade). Na época clássica a principal forma tomada pelo conhecimento seria a "representação". Sade teria, no entanto, levado esse imperativo a sério demais: ao tentar fazer todas as formas do desejo serem representadas (inclusive suas variações no tempo e no espaço, de onde advém seu interesse antropológico), evidenciou ou descobriu um limite à própria capacidade linguístico-intelectual de representar (FOUCAULT, 1966, p. 222). Kant, ao propor a existência de todo um campo de direito incognoscível, mas que seria repositório ou fonte do que se conhece, permitiu reconfigurar os sistemas de conhecimento para dar conta de integrar aquele "manto de penumbra" que Sade descobrira. Esse novo objeto que o pensamento kantiano viabilizaria, e que ao longo da modernidade encontrará inúmeras formas, Foucault o chama simplesmente de "homem", e seu estudo são as ciências humanas. A antropologia enquanto ciência surgiria dessa nova configuração do pensamento, buscando elucidar aspectos históricos desse novo "objeto" de estudos (FOUCAULT, 1966, p. 389).

De Hobbes, pode-se dizer ser ele o inaugurador do pensamento político-filosófico na modernidade (BARROS, 2013, p. 75). Isso se dá, dentre outros motivos, na ruptura que, em seu $O$ Leviatã, propõe com o pensamento aristotélico acerca do tema. Pelo que consta, o modo hobbesiano de colocar a questão da política instaurou o campo dentro do qual as disputas acerca do tema se deram no pensamento moderno. Nesse 
sentido, algumas das tópicas fundamentais da argumentação hobbesiana passaram a ser recorrentes entre seus contemporâneos e posteriores, como a investigação acerca do estado de natureza, a passagem desse para o estado de sociedade, o contrato social, a precedência da existência individual sobre a social, etc. No entanto, dizer que formas e tópicos da argumentação hobbesiana se tornaram paradigma ou referência para a reflexão posterior não pode de modo algum ser compreendido como afirmação da mera adesão desses outros pensadores a tais teses e ideias. 0 que se verificou foi, em larga medida, o contrário: muitos deles discordaram veementemente de Hobbes (e entre si), instaurando uma rica discussão filosófica acerca da legitimidade e do surgimento da vida social e política. Não parece ser descabido dizermos que esse debate marcou o momento da filosofia moderna, ao menos no séc. XVIII. Não só é nesse contexto que Sade se insere, mas ele pode ser lido como um exemplo ao mesmo tempo típico e excêntrico desses modos de lidar com o legado político hobbesiano.

Ora, assim como Foucault, acreditamos poder dizer que Sade ocupa nessa configuração do pensamento antropológico um lugar diferenciado. Sade foi contemporâneo da Revolução Francesa e repetidamente afirmou seu apoio e filiação a ela e ao movimento Iluminista. Fortemente marcado pela leitura de autores como Hobbes, D'Holbach, La Méttrie, os enciclopedistas, etc., Sade concordava em boa medida com o racionalismo da época e com a ideia de que a razão deveria permear e informar os diversos âmbitos e modos da vida, tanto individual quanto coletiva. Aliás, é de se considerar que se Hobbes e os relatos de viagem desde o século XVI traziam a visão da superioridade eminente dos povos europeus sobre os ameri- canos, foi contemporaneamente a Sade que essa ideia tomou sua forma bem-acabada e que a matriz cultural que a embasa se consolidou de todo. No entanto, leitores de Sade insistem em apontar que há algo no mínimo estranho e problemático na versão sadeana do iluminismo; alguns chegando mesmo a dizer de Sade ser um crítico radical da racionalidade moderna e da modernidade como um todo. Sem buscar entrar a fundo nesse debate ou marcar posições, de fato, ao menos em uma primeira leitura, parece existir algo de dissonante no uso que Sade faz de ideias e conceitos centrais da modernidade. Isso é particularmente notável no trecho que buscamos comentar.

Em sua dissertação sobre o crime, o personagem Pio VI começa com a questão própria do pensamento político da época: se perguntará sobre qual conduta é prescrita pela natureza (SADE, 1998, p. 870). Por sinal, é no seio dessa argumentação, como "exemplos feitos para [...] provar que em todos os tempos o homem fez suas delícias em destruir, e a natureza os seus em permiti-lo" (SADE, 1998, p. 886), que encontramos a argumentação antropológica. Clara Castro, seguindo uma indicação de Jean Deprun, nota como nos discursos da História de Juliette existe uma intensificação do pensamento sobre a função e a necessidade do crime. Essa gradação passa por dois estágios (CASTRO, 2015, p. 226): primeiramente a função sincrônica do crime. Essa concepção é presente, por exemplo, no discurso de Noirceuil. Segundo esse libertino, "um universo totalmente virtuoso, não saberia subsistir um minuto; a mão sábia da natureza faz nascer a ordem da desordem, e sem desordem ela não chegaria a nada" (SADE, 1998, p. 331). Essa concepção tende mais a um "amoralismo" que à imoralidade pura e simples. Entende-se que, para a natureza, 
virtude e crime compõem um todo necessário. Sem um desses, a natureza rapidamente sucumbiria pela falta de dinamismo e desordem necessária à criação de novos seres e movimentos. Dessa forma, o pensamento e a vida moralistas têm sua razão de ser, apenas sendo um problema quando se excedem e desejam impedir a imoralidade.

Essa tese, no entanto, apenas tem validade em curto prazo. Em longo prazo, sendo o crime naturalmente mais ativo e forte, ele tende a franquear os limites postos pela moral, levando à destruição generalizada. É precisamente nisso que consiste a teoria proposta por Pio VI, das duas naturezas: uma visão diacrônica do crime, segundo a qual ele é, ao mesmo tempo necessário e nocivo à natureza. Nessa cosmovisão sadeana há de se falar em uma "dualidade da natureza, dissociada em primeira e segunda, e seu assujeitamento às suas próprias leis" (MENGUE, 1996, p. 47). A natureza segunda consiste na organização da matéria nos reinos mineral, vegetal e animal, e nas regras que garantem a passagem de um ao outro. Trata-se da natureza imediatamente observável, que, através da conversão das matérias vivas violentamente desorganizadas em matérias minerais a serem reabsorvidas pelos seres vivos, propicia um equilíbrio dinâmico entre crime e virtude na configuração do mundo. É notável como a virtude, pensada como um impulso de conservação e manutenção da ordem, tem precedência para essa natureza segunda, uma vez que o crime não causa verdadeiro desarranjo, apenas um dinamismo que é reintegrado na manutenção das regularidades naturais.

No entanto, para a natureza primeira a virtude nunca pode ter qualquer relevância. As duas naturezas não se coadunam: a segunda supõe um ordenamento que garanta sua constante reprodução, mas a natureza dita primeira é justamente aquela que cria esses funcionamentos regrados da natureza segunda, os quais, a rigor, seriam contingentes: nada diz ser necessário que existam três reinos nos quais a matéria se organiza, e não dois ou quatro. A princípio, assim como a natureza segunda necessita de alguma medida de violência e destruição para manter sua potência criadora, a natureza primeira precisaria que as próprias leis da física e da conservação da matéria pudessem ser destruídas para que disponibilizassem seus "componentes" para a criação de novas regularidades e regras. Daí que a destruição, nessa natureza primeira, cumpra um papel diferente: sendo como que uma "metarregularidade", é, ela mesma, irregular. Leia-se, opera fundamentalmente através da destruição, sendo diretamente imoral (MENGUE, 1996, p. 48). Daí que, em se tratando de libertinagem, constantemente os libertinos vejam seus desejos frustrados. Não bastaria matar: para realmente cumprir o que a natureza comanda, o libertino precisaria ter a força para deslocar os astros de suas órbitas, desvirtuar a gravidade, etc.

Seu próprio prazer e bem-estar não são limites a essa ânsia destruidora: Clairwil repreende Juliette pois ela apenas comete o crime quando excitada. Para o libertino principiante, é até que comum que o desejo pelo crime surja a partir do sexo. Mas para o libertino experiente e consumado, a relação se inverte. 0 crime vale por si e é o termo principal da conduta libertina, uma vez que é a consecução de seu sistema filosófico naturalista. 0 ideal da apatia serve como que um corolário às aspirações libertinas: o prazer importa menos que a destruição; a natureza ordena esta, e aquele serve apenas de sinal que ela dá para indicar suas verdadeiras intenções. Clairwil afirma seu desejo de cometer um crime que ultrapasse sua 
vida e se perpetue após sua morte, a ponto de generalizar a desordem e corromper a própria estrutura do universo. A destruição da natureza segunda, a grande aspiração dos libertinos mais sábios, envolveria a morte do próprio. Mengue conclui: o crime é preferível à virtude pois assim o libertino responde melhor às injunções da verdadeira natureza, mesmo que em alguma medida isso signifique contradição consigo mesmo (MENGUE, 1996, p. 52).

Como brevemente mencionamos, é esse desejo de nada, essa negatividade intrínseca e destrutiva do desejo humano, que, em primeiro lugar, a antropologia de Sade busca mostrar. É observando a natureza e buscando imitá-la que o libertino descobre a lei de sua conduta. Nos povos primitivos, o pensamento filosófico europeu, desde Hobbes, encontrou o avatar do que considerava como sendo o homem natural: um homem pré-político, pois sem Estado. Sade não se furta a esse modo moderno de reflexão política, mas extrai dele consequências por inteiro contrárias àquelas de seus autores principais. Pudemos ver as relações entre a matriz cultural iluminista e um pensamento de tipo evolucionista. 0 comentário antropológico de Pio VI mostra que os povos indígenas, asiáticos, africanos, os primitivos em geral, são brutos, violentos e não têm na razão um valor tão central para suas formas de vida. Sade, Hobbes, e toda uma tradição evolucionista de pensamento estão de acordo neste ponto. Mas, para o libertino, é justamente por ser agressivo e sem Estado que o primitivo é muito superior ao homem europeu médio:

Não escutemos senão o órgão sagrado da natureza ... certos de que ele contrariará sempre os absurdos princípios da moral humana e da infame civilização: credes vós, portanto, que a civilização ou a moral fizeram o ho- mem melhor? Não o imagine [...] Evite supô -lo; um e outro não fizeram senão amolecer, fizeram esquecer as leis da natureza que lhe fizeram livre e cruel (SADE, 1998, p. 880)

Observando mais algumas passagens etnográficas desse discurso papal -

Até a translação do Império Romano, os pais faziam morrer aqueles de seus filhos que lhes desagradavam, qualquer a idade que tivesse.

Em diversos artigos do Pentateuco pode-se ver que os pais tinham direito de vida e morte sobre seus filhos (SADE, 1998, p. 887)

- percebemos um novo dado: ao comentário sobre outros povos mistura-se o comentário sobre o passado do ocidente. Isso mostra que os povos não europeus são capazes de acessar algumas formas e manifestações da violência que nós já pudemos, mas não podemos mais. 0 que o personagem faz é comparar os povos europeus com os "primitivos" e mostrar como, em certo desenrolar histórico, dominamos melhor as formas da racionalidade e da técnica. No entanto, quando se fala do critério axiológico constitutivo do pensamento evolucionista, aqui Sade difere significativamente. Existiu, na história dos povos europeus, uma tendência a passar de estados de maior violência para uma vida racionalizada e organizada política e juridicamente sob o nome do Estado. Esse caminho foi percorrido apenas parcialmente por outros povos; na melhor das hipóteses, eles racionalizaram suas formas de violência. E, no entanto, isso significa justamente que a sociedade ocidental europeia é menos "evoluída" ou, enfim, que por ser "mais evoluída" é menos forte. A moral cristã serviu apenas para fazer o homem esquecer daquilo que lhe ordena sua natureza mais íntima. Tendo escrito antes de Sumner-Maine, podemos ver como Sade põe ao contrário aspectos importantes da 
caracterização do evolucionismo segundo seus argumentos enquanto mantém a narrativa histórica. Sade nos apresenta o espelho invertido do pensamento evolucionista; é como se se tratasse de um "desevolucionismo" ou "involucionismo".

Mas há um segundo ponto. É significativo que a dissertação do Papa não seja sobre a violência, sobre a maldade, a imoralidade, etc., mas sim sobre o crime (especialmente o crime de assassinato). Existe uma tensão que perpassa vários dos discursos libertinos sadeanos no que diz respeito a essa tese da naturalidade do crime. Isso pois o crime é, antes de tudo, um termo jurídico; apenas existe crime se há, anteriormente, uma lei que proíbe uma conduta, de modo a defini-lo. Se é da natureza do homem o crime, deve haver também uma lei logicamente anterior, da qual esse crime é a transgressão. Sendo assim, a natureza deve prescrever simultaneamente uma lei e sua infração. De fato, essa parece ser uma questão pendente para o pensamento libertino. Segundo o Papa:

[...] longe de agradecer essa natureza inconsequente do pouco de liberdade que ela nos deu para cumprir os pendores inspirados por sua voz, blasfememo-la do fundo de nosso coração, de nos ter tanto diminuído nossa carreira [...] ultrajemo-la, detestemo-la, por nos haver deixado tão pouco de crimes a fazer [...] (SADE, 1998, p. 885).

Essa é uma tópica comum na argumentação libertina. 0 desejo de cometer crimes se encontra em descompasso com a efetiva possibilidade de fazê-lo. Impossibilidade que advém não da falta de forças do coração viciado do homem, mas justamente da lassidão da lei natural. A natureza exige a destruição, o assassinato, o infanticídio, etc. Sendo assim, quem os comete não está de fato a cometer um crime senão aos olhos dos homens, cujas leis o estudo antropológico já mostrou serem simplesmente arbitrárias. Aos olhos da natureza, no entanto, não há ultraje possível; toda ação libertina serve, de um modo ou de outro, a seus fins. Nessa lei dúplice da natureza, que demanda a infração de uma proibição mas não proíbe nada a ser infringido, o libertino encontrase inevitavelmente em falta e culpa. Como diz Sade em seu poema $A$ Verdade:

E que o infame Deus, do qual querem me alarmar/não seja concebido por mim senão para blasfemar./Sim, vã ilusão, minha alma te detesta/E para melhor te convencer, aqui ela protesta./Gostaria que por um momento tu pudesses existir/Para gozar do prazer de melhor te atingir (SADE, 1973, p. 81).

Ao desejo de crime é correlato um desejo de lei a ser transgredida; paradoxalmente, o libertino ressente o fato de que a natureza lhe dê o direito de matar: "aquele que obedece à lei não é e não se sente justo por conta disso. Pelo contrário, ele se sente culpado, ele é, de partida, culpado, e tão mais culpado quanto mais lhe obedece estritamente" (DELEUZE, 1967, p. 74).

Livia Gomes (2017, p. 14), em sua tese, nota justamente como esse tipo de funcionamento é central na obra de Sade para a constituição de sua linguagem literária. É importante considerar que o prazer é o articulador central dessa linguagem. Sade equipara de forma bastante direta o prazer sexual e o discurso científico filosófico:

Ainda, devido a esse paralelismo ou equivalência entre discurso e sexo, "a sensação, diversamente transformada, é fonte e critério de verdade", capaz de decidir por ou contra um argumento. Toda ideia precisa passar pelo circuito completo antes de poder ser aceita ou rejeitada. Como diz Le Brun sobre o próprio Sade: "aquilo que sua cabeça lhe prova, seu corpo redescobre, mas também aquilo que seu corpo lhe prova, sua cabeça o 
redescobre". Assentimento e prazer podem se tornar, neste sentido, termos correlatos ou até intercambiáveis (GRANÉ DINIZ, 2018, p. 110).

Mas, se em alguma medida, o ato sexual tem de adquirir uma organização racional, é muito mais importante o modo como o discurso racional passa a participar da desrazão própria ao ato sexual. Especificamente, assim como cada corpo é dotado de um desejo próprio e singular, o discurso filosófico abandona a universalidade de um enunciado impessoal em troca da perspectividade da fundamentação de cada prazer: "Ah, Saint-Fond!, diz Clairwil, como seria fácil fazer ver que teu sistema não é senão o fruto dessas paixões que você quer que renunciemos ao estuda-lo" (SADE, 1998, p. 538). Nesse sentido, a dualidade que ordena as obras de Sade - cenas sexuais e discursos filosóficos - faz do próprio livro lido um instrumento e mecanismo de prazer: assim como na cena de Delbène os corpos e as palavras são dois polos entre os quais circula a energia libidinal, o livro de Sade é, em relação a nosso corpo, um dos polos que instaurará, pelo ato da leitura, um prazer de cunho intelectual e sexual.

Bataille nota como a derrogação de um funcionamento unívoco ou utilitário da linguagem na obra de Sade passa pela articulação entre linguagem e violência. A linguagem seria, de princípio, recusa da violência. Ela tem por finalidade primeira ordenar e organizar uma natureza que nos é fundamentalmente hostil, que coloca em risco constante nosso ser e nossa existência. De um ponto de vista histórico-genealógico, seu surgimento pode ser retraçado ao momento no qual os homens começaram a trabalhar. 0 trabalho é, para o homem, a forma de negar a natureza pela criação de um mundo propriamente humano; apartando-se dela na busca de subtrair-se a um movimento de violência que lhe põe em risco constante e iminente de morte. Para trabalhar, esse homem precisa criar uma forma de racionalidade permita distinguir meios de fins, causas e efeitos, etc. (BATAILLE, 1957, p. 51): "é pelo trabalho que a consciência clara e distinta dos objetos nos foi dada" (BATAILLE, 1957, p. 179). A ideia da busca pela clareza e distinção - poder-se-ia dizer, pela descoberta dos sentidos unívocos nos quais a linguagem se refere a seus objetos - esteve inscrita na linguagem desde o momento que ela se conformou; inclusive em seus usos políticos. Em um trabalho muito interessante, Philip Pettit mostra como um aspecto relevante da solução hobbesiana para os conflitos no estado de natureza está na criação de sentidos únicos pelo soberano para termos centrais da vida político-jurídica:

Não apenas o acesso à república torna-se possível pelo poder do contrato e da incorporação que as palavras introduzem. A república ela mesma é caracterizada em grande parte, como nós veremos, pela ordem das palavras que ela monta. Está associada com a aparição das palavras "justo" e "injusto", com a invenção da propriedade e da definição de palavras como "meu" e "seu", e de forma mais genérica com a ordenação de palavras, como "bem" e "mau", que tipicamente levam as pessoas às vias de fato. Todas essas palavras vêm a ter em cada boca o único, indisputável sentido que é autorizado pelo soberano (PETTIT, 2008, p. 115, realce nosso)

Hobbes considera que a linguagem se torna unívoca para fazer evitar a violência; necessidade que ele extrai como corolário da própria natureza huamana. Bataille mostra como em Sade esse funcionamento é suposto, mas apenas para que, por um subterfúgio, faça a violência penetrar e contaminar a linguagem. Na literatura de Sade, a linguagem opera diretamente sobre o corpo; não 
serve para designar e denominar justamente porque ela derroga a univocidade ideal do sentido através da violência.

Articulação que vimos operar entre os indígenas. As cicatrizes da tortura sobre o corpo dos jovens índios serviriam, como as palavras no contrato hobbesiano, para a inscrição de uma linguagem que denota a lei. Como em Hobbes, uma lei da igualdade. Mas, nesse caso, também lei da violência. Uma lei que, de partida e por necessidade, vem a dizer do pertencimento a um grupo em exclusão de todos os outros, por meio da qual não se evita, mas se instaura a guerra entre os vários grupos e se impede sua unificação na figura de um Estado, alienador de suas liberdades. No âmbito de sua análise da obra de La Boétie, Clastres buscará mostrar como há uma afinidade forte entre certo princípio aglutinador na política - do qual decorre o Estado - e a recusa da violência. Clastres fala em uma lógica da unificação, que é o fundamento ao mesmo tempo histórico, lógico e moral do surgimento do Estado. A negação e o contrário dessa lógica, a busca pela difusão do poder na multiplicidade de indivíduos dentro de um grupo e na multiplicidade de grupos que (literalmente) lutam para se diferenciar, é a sociedade indígena da guerra e da violência. A lógica da multiplicidade se revela na linguagem da lei da tortura: são sociedades cuja lei não é escrita pois a escrita da lei significa essencialmente sua articulação em separado dos corpos que a vivem. Dizendo de outra forma, o Estado se fala e articula seus funcionamentos sociais na linguagem de uma lei que se separa dos corpos que governa, que se enuncia através da univocidade de uma fala que se propõe racionalizada, condição ao menos suposta para a regulamentação jurídica.

Para Clastres, a constituição política da sociedade indígena visa mais que impedir a emergência do Estado. Observando relatos de suas religiões, Clastres conclui que a luta contra a centralização do poder responde não apenas à lógica político-econômica de sua organização, mas a um aspecto fundamental de sua cultura: "que diz o pensamento guarani? Ele diz que o Um é o Mal" (CLASTRES, 1974, p. 148):

A terra imperfeita, onde "as coisas em sua totalidade são uma", é o reino do incompleto e o espaço do finito, é o campo de aplicação rigoroso do princípio de identidade. Pois dizer que $\mathrm{A}=\mathrm{A}$, que isso é isso, e que um homem é um homem, é declarar, ao mesmo tempo, que A não é não-A, que isso não é aquilo, e que os homens não são deuses. $\mathrm{No}$ mear a unidade nas coisas, nomear as coisas em sua unidade, equivale a assinalá-las com o limite, a finitude, a incompletude (CLASTRES, 1974, p. 149).

A Terra esperada será sem mal pois sem unidade. Podendo cada coisa ser muitas e ser infinita, será uma terra sem privação. Mas, diferente de um paraíso cristão, não será uma terra sem violência:

O pai, escreve padre Nóbrega [no séc. XVI], convoca os índios a não mais trabalhar, não mais ir aos campos, lhes prometendo que as plantas de seus jardins crescerão sozinhas [...] que as flechas caçarão por seus mestres, que eles matarão vários inimigos, que eles lhes capturarão em grande número, que comerão (NAVET, 2002).

É um paraíso de guerra e canibalismo, uma utopia de violência. Mais ainda, de violência gratuita, não exercida mais pela necessidade de disputar um território ou de buscar alimento. Na terra sem Mal se articulam violência e liberdade em um sentido radical: o homem é livre para ser o que bem entender, mesmo deixar de ser homem, para ser mais de uma coisa ao mesmo tempo (cf. NAVET, 2002). A tortura nos ritos de passagem serve como preparação para o ingresso 
futuro nesse mundo em que ele será não só homem, mas mineral, vegetal e animal: "na solidão, ele [o adolescente] se esforça para colocar em acordo seu corpo e seu ser interior, tentando, ao mesmo tempo, se unir com a terra, as criaturas animais e os seres vegetais que se encontravam nos locais de sua visão" (NAVET, 2002). Se tentarmos pensar ambos os aspectos que vimos decorrer da argumentação antropológica de Sade, talvez possamos dizer que Sade descobrira, à sua maneira (mas não por acaso), esse funcionamento. Percebeu através dos relatos de viajantes sobre as sociedades indígenas que o problema do Estado é, antes de ser simplesmente político, uma questão que se articula entre linguagem e moral. A lei do libertino de Sade é justamente uma lei que, assim como a das torturas e ritos de passagem, se inscreve sobre o corpo. Assim como a lei indígena, trata-se de uma lei da cumplicidade, a qual é inesquecível, irrevogável e intransgredível, na medida em que se está no próprio corpo tomado pelo prazer sensual propiciado pela leitura. Sade, ao explorar o aspecto equívoco de sua linguagem literária, consegue apontar o caminho para reverter a lógica que enxerga na unidade da própria linguagem um fundamento e possibilidade da unificação política. Mais que simplesmente argumentar contra o Estado no âmbito da política, Sade coloca em operação um mecanismo linguístico que desvela uma lógica contrária à que o embasa e possibilita: linguagem ao mesmo tempo da violência e do prazer, que toma a forma de cada corpo com que tem contato, criando uma liberdade radical para a experiência ilógica e plúrima do prazer.

\section{Referências:}

BARROS, A. 0 Conceito de Soberania na Filosofia Moderna. São Paulo: Barcarolla. 2013.
BATAILLE, G. L'Erotisme. Pais: Les Editions de Minuit. 1957.

CASTRO, C. Os Libertinos de Sade. São Paulo: Iluminuras. 2015.

CLASTRES, P. Arqueologia da Violência. São Paulo: Cosac-Naify. 2014.

CLASTRES, P. La Société Contre L'État. Paris : Éditions de Minuit. 1974.

CLASTRES, P. Recherches d'Anthropologie Politique. Paris: Seuil. 1980.

DELEUZE, G. Présentation de Sacher-Masoch. Paris: Éditions de Minuit. 1967.

ELLIOT, E. The Evolutionary Tradition in Jurisprudence. Yale legal School Scholarship Repository, Yale, vol. 85, n‥ 38, p. 38-94, 1985.

FAUSTO, Carlos. Da inimizade: forma e simbolismo da guerra indígena. In NOVAES, Adauto. A outra margem do ocidente. São Paulo: Companhia das Letras, p. 251-282, 1999.

FOUCAULT, Michel. Les Mots et les Choses: Une Archeologie des Sciences Humaines. Paris: Gallimard. 1966.

GOMES, L. 0 Corpo por Fazer: Equivocidade Enunciativa nas Três Versões de Justine. 2017. 246 f. Tese (Doutorado em Teoria Literária e Literatura Comparada) - Universidade de São Paulo - Faculdade de Filosofia, Letras e Ciências Humanas. São Paulo, 2017.

GRANÉ DINIZ, Guilherme. Essas Doces Ações que vós chamais de Crimes: Crítica à Modernidade e Crítica do Direito em Sade. 2018. 298 f. Dissertação (Mestrado em Filosofia e Teoria Geral do Direito) - Universidade de São Paulo Faculdade de Direito. São Paulo, 2018.

HOBBES, T. Os Pensadores - Hobbes. São Paulo: Abril Cultural. 1973.

LELY, G. Vie du Marquis de Sade, vol. II. Madri: Tête-de-Feuilles. 1973.

MENGUE, P. L'Ordre Sadien: Loi et Narration dans la Philosophie de Sade. Paris: Éditions Kimé. 1996.

NAVET, Eric. La quête de la $\ll$ Terre sans Mal >> chez les peuples traditionnels: l'Exemple des Tupi-Guaranis (Amérique du Sud). Dis- 
ponível em <https://journals.openedition.org/ leportique/149>. Último acesso: 09/10/2019.

PETTIT, P. Made with Words: Hobbes on Language, Mind and Politics. Princeton: Princeton University Press. 2008.

SADE, D.A.F. Oeuvres, vol. II. Paris: Gallimard. 1990.

SADE, D.A.F. Oeuvres, vol. III. Paris: Gallimard. 1998.
SADE, D.A.F. Oeuvres Complètes, vol. XIV. Madri: Tête-de-Feuilles. 1973.

SUMNER-MAYNE, H. Ancient Law. Londres: J. M. Dent \& Sons. 1936.

VIVEIROS DE CASTRO, Eduardo. Metafísicas Canibais. São Paulo: Ubu Editora, N-1 Ediçoes. 2018.

Recebido em: 15/10/2019

Aceito em: 13/01/2020 